\title{
Farklı sıcaklıkların hardaliyenin depolama stabilitesi üzerine etkisi
}

\section{Effect of different temperatures on hardaliye quality during storage}

\author{
Buket AŞKIN ${ }^{1}$ iD \\ ${ }^{1}$ Kırklareli üniversitesi, Mühendislik Fakültesi, Gıda Mühendisliği Bölümü, Kırklareli
}

\section{To cite this article:}

Aşkın, B. (2019). Farklı sıcaklıkların hardaliyenin depolama stabilitesi üzerine etkisi. Harran Tarım ve Gıda Bilimleri Dergisi, 23(1): 13-21. DOI:10.29050/harranziraat.4094 34

Address for Correspondence: Buket AŞKIN

e-mail:

buketaskin@klu.edu.tr

Received Date:

26.03.2018

Accepted Date:

26.10.2018

\section{Öz}

Hardaliye, Türkiye lezzet haritasına Kırklareli'den işaretli, olgunlaşmış üzümlerden elde edilen alkolsüz, buruk içimi ve ferahlatıcı özellikleriyle karakteristik bir içecektir. Çalışmamızda, Kırklareli ilinde bulunan üzüm bağlarında yetişen mor-siyah üzüm çeşitlerinden papazkarası üzüm çeşidi kullanılarak hardaliye elde edilmiş, toplam antosiyanin miktarı belirlenmiş ve depolama özellikleri kinetik olarak değerlendirilmiştir. Böylece, ısıtma ve depolama süresi boyunca, hardaliye antosiyaninlerinin parçalanmasına ilişkin kinetik veriler ortaya konmuştur. Hardaliyenin depolama süresince, antosiyaninlerindeki parçalanma birinci derece kinetik modele uygun olarak gerçekleşmiştir. Beklendiği gibi, yüksek sıcaklıklarda antosiyaninler daha hızlı parçalanmıştır. Hardaliyelerde antosiyaninlerin parçalanmasına ilişkin yarılanma süreleri 4 ${ }^{\circ} \mathrm{C}$ ve $20{ }^{\circ} \mathrm{C}$ sıcaklıklarda sırasıyla 22.5 ve 10.34 gün olarak saptanmıştır. Depolama sürecince, hardaliye örneklerinin polifenol içeriğinde $4{ }^{\circ} \mathrm{C}$ ve $20^{\circ} \mathrm{C}$ için sırasıyla $\% 21$ ve $\% 24$ kayıp meydana gelmiştir. Antioksidan aktivite içeriği ise önemli değişim görülmemiş, her iki sıcaklık değerinde de \%12-13 oranında azaldığı saptanmıştır. Antosiyaninlerin sıcaklığa dayanımının belirlenebilmesi için aktivasyon enerjisi ve $Q_{10}$ değerleri belirlenmiştir.

Hardaliye antosiyaninlerin parçalanmasına ilişkin aktivasyon enerjisi $4{ }^{\circ} \mathrm{C}-20{ }^{\circ} \mathrm{C}$ sıcaklık aralığında $64.76 \mathrm{~kJ} \mathrm{~mol}^{-1}$ bulunmuştur. Elde edilen veriler, hardaliye antosiyaninlerinin 4 ${ }^{\circ} C^{\prime}$ de daha stabil olduğunu ve hardaliyenin tüketime kadar düşük sıcaklıkta muhafaza edilmesi gerektiğini ortaya koymaktadır.

Anahtar Kelimeler: Antosiyanin, Depolama, Hardaliye, Kinetik, Renk

\section{ABSTRACT}

Hardaliye is a non-alcoholic beverage, derived from ripe grape signed with Kırklareli in Turkey flavor map, has some characteristics as sour taste and refreshing properties. In this research, hardaliye was produced with purple-black grape cultivated in Kırklareli, total monomeric anthocyanin content was determined and interpreted with kinetic properties. Thus, the kinetic parameters were determined for the degradation of anthocyanins in hardaliye and storage parameters were determined.

During storage time of hardaliye, anthocyanin degradation kinetic was fitted to the first order reaction. As expected, there was higher degradation of anthocyanins at higher temperature. Half-life periods for anthocyanin degradation in hardaliye samples were 22.5 and 10.34 days at 4 and $20^{\circ} \mathrm{C}$, respectively. There were loss of 21 and $24 \%$ of polyphenol contents for storage period at $4{ }^{\circ} \mathrm{C}$ and $20^{\circ} \mathrm{C}$, respectively. Otherwise, there were not significant changes for antioxidant activity of hardaliye samples, there were only $12-13 \%$ losing for both samples.

Temperature dependence of anthocyanins was determined by calculating activations

Key Words: Anthocyanins, Color, Hardaliye, Kinetics, Storage. \footnotetext{
energy $\left(E_{a}\right)$ and $Q_{10}$ values. $E_{a}$ value for the degradation of anthocyanins in hardaliye was $64.76 \mathrm{~kJ} \mathrm{~mol}^{-1}$ at $4{ }^{\circ} \mathrm{C}$ to $20^{\circ} \mathrm{C}$, respectively. According to the results, anthocyanins of hardaliye were more stable at $4{ }^{\circ} \mathrm{C}$ and it should be stored at low temperatures until consumption.

(c) Copyright 2018 by Harran University Faculty of Agriculture. $\begin{array}{ll}\text { Available } & \text { on-line } \\ \text { www.dergipark.gov.tr/harranziraat }\end{array}$ 


\section{Giriş}

Hardaliye, geleneksel olarak üretilen değerli bir içecektir. Trakya'da özellikle Kırklareli ve yakın köylerinde yaz aylarında hasat edilen üzümün değerlendirilmesi ve diğer mevsimlerde de tüketilebilmesi için üretilen bir alternatif üründür. Üzüm suyundan üretilmesinden dolayı oldukça besleyici bir içecektir (Coşkun, 2001; Arıcı, 2007). Hardaliye ile yapılan çok az bilimsel çalışmaya rastlanmış olmasına karşın, koyu renkli üzümlerden yapılıyor olması nedeniyle fenolik bileşenler ve monomerik antosiyaninlerce zengin olduğu mevcut çalışmalarda yer almıştır (Arıcı ve ark., 2011). Ayrıca üzümden elde edilen ürünlerin, bileşimlerindeki yüksek askorbik asit ve fenolik bileşenler nedeniyle antioksidan etkiye sahip oldukları, içerdikleri polifenollerle kardiyovasküler hastalıklara karşı koruyucu etki gösterdikleri bilinmektedir (Castilla ve ark., 2006; Davalos ve ark., 2006; İnanç ve Yüksel, 2018).

Tüm fermente gıdalarda olduğu gibi, hardaliye de birçok ürüne kıyasla kısa raf ömrüne sahip ve depolama koşullarına dikkat edilmesi gereken bir üründür (Anonim, 2012; Arıcı ve ark., 2011). Hardaliye, Kırklareli yöresi için önemli bir maddi kaynak oluşturmaktadır. Bu nedenle, depolama stabilitesinin belirlenmesi gerek üretimi gerekse tüketimi açısından büyük önem taşımaktadır.

Renk, hardaliye gibi üzümden üretilen içecekler için tüketici tercihini ve duyusal kabul edilebilirliği etkileyen önemli bir kalite kriteridir. Üzüm sularında arzu edilen kırmızı renk antosiyanin varlığından kaynaklanmaktadır. Üzümün içermiş olduğu antosiyanin içeriği çeşit, olgunluk, hasat yılı, çevre koşulları vb. gibi birçok faktöre bağlı olarak değişim göstermektedir (Mazza ve Francis 1995). Üzümde ve dolayısıyla hardaliyede bulunan başat antosiyaninler malvidin, delfidin, peonidin, petunidin, siyanidin ve pelargonidindir (Tiwari ve ark., 2010). Bu antosiyaninlerin stabilitesi sıcaklık ve ürün prosesi başta olmak üzere $\mathrm{pH}$, oksijen, enzimler, kopigment ve metal iyonu varlı̆̆ı, sülfürdioksit, şekerler ve onların parçalanma ürünleri olmak üzere birçok faktöre bağııdır (Mazza ve Miniati 1993; Pozo-Insfran ve ark.,
2007; Tiwari et al. 2010; Pala ve Toklucu, 2013).

Üzüm suyunda raf ömrünü uzatmak amacıyla veya farklı amaçlarla uygulanan en yaygın olarak uygulanan koruma yöntemi ısıl muamelelerden önemli miktarda etkilenmektedir (Pala ve Toklucu, 2013). Isıtma sırasında antosiyaninlerin parçalanması ve polimerizasyonu biyolojik aktivitelerini de etkilemektedir (Pozo-Insfran ve ark., 2006; Brownmiller ve ark., 2008; Hager ve ark., 2008; Turfan ve ark., 2011). Bir çok farklı çalışmada, ısıl işlem sırasında antosiyanin kaybı ile birlikte antioksidan aktivitenin de azaldığı yer almıştır (Sadilova ve ark., 2007; Pozo-Insfran ve ark., 2006). Ancak, bu durumun antioksidan aktiviteyi etkilemediğini gösteren çalışmalar da mevcuttur (Brownmiller ve ark., 2008; Hager ve ark., 2008).

Çalışmamızda hardaliye örneklerinin farklı sıcaklıklarda depolanması sırasında antosiyanin kaybına ilişkin reaksiyon derecesi belirlenmiş ve bu reaksiyonlara ilişkin kinetik katsayılar (hız sabitleri, $t_{1 / 2}$ değerleri, aktivasyon enerjisi ve $Q 10$ değerleri) hesaplanmıştır. Ayrıca, depolanma sürecinde antioksidan aktivite değeri ile polifenol miktarındaki değişim de tespit edilmiştir.

\section{Materyal ve Yöntem}

Hardaliye üretiminde kullanılan üzüm çeşidi için hem sofralık hem de şaraplık bir çeşit olan papazkarası tercih edilmiştir. Çalışmada $100 \mathrm{~kg}$ papazkarası üzüm kullanılmış olup, 2016-2017 hasat yılında Kırklareli ilinde yetiştirilmiş olan üzümlerden temin edilmiştir. Hardaliye üretiminde üzüm dışında siyah hardal tohumu (Brassica nigra L.) ve vişne yaprağı (Prunus cerasus L.) kullanılmış olup, ayrıca koruyucu olarak sodyum benzoat ve potasyum sorbat ilave edilmiştir.

\section{Hardaliye üretimi}

Hardaliye üretimi Kırklareli Üniversitesi Mühendislik Fakültesi Gıda Mühendisliği Bölümü Laboratuvarında gerçekleştirilmiş olup, fermantasyon için 2 adet $20 \mathrm{~L}$ hacminde plastik ve musluklu bidon kullanılmıştır. Öncelikli olarak 
üzümler yıkanmış, sap ve çöp ayrılmış, hafifçe ezilmiş ve sırasıyla siyah hardal tohumu $(\% 1, w / v)$, koruyucu $(\% 0.1, w / v)$ sodyum benzoat ve \%0.1 $(\mathrm{w} / \mathrm{v})$ potasyum sorbat) ile vişne yaprağı $(\% 1, \mathrm{w} / \mathrm{v})$ ilave edilmiştir. Örnekler $22{ }^{\circ} \mathrm{C}^{\prime}$ de 30 gün süre ile fermente edilmiştir. Fermantasyonun tamamlanmasının ardından üzüm çekirdeği ve posanın uzaklaştırılması amacıyla filtre edilmiş, $250 \mathrm{~mL}$ hacmindeki amber renkli şişelere doldurularak farklı iki sıcaklıkta $\left(4{ }^{\circ} \mathrm{C}\right.$ ve $20^{\circ} \mathrm{C}$ ) 60 gün süre ile muhafaza edilmiştir. Kinetik değerlendirmenin yapılması amacıyla 0, 15, 30, 45 ve 60. günlerde her iki depolama sıcaklığından örnek alınarak hedeflenen özellikleri değerlendirilmiştir.

\section{Genel bileşime yönelik analizler}

Briks: Refraktometrik olarak saptanmış olup, bu amaçla dijital refraktometre kullanılmıştır. $\mathrm{pH}$; potansiyometrik olarak saptanmıştır.

Titrasyon asitliği: pH-metre ile izlenerek yürütülen titrasyonla saptanmış ve bu amaçla IFU tarafından (1968) önerilen işlemler uygulanmıştır.

\section{Toplam monomerik antosiyanin miktarının} belirlenmesi

Bu amaçla, Fuleki ve Francis (1968) tarafından önerilen ve Giusti ve Wrolstad (2005) tarafından geliştirilen $\mathrm{pH}$ diferansiyel metodu kullanılmıştır. Absorbans ölçümünden once bulanıklığın giderilmesi amacı ile örnekler 0.45-mm polivinilden fluorid (PVDF) filtreden (Millipore, Bedford, MA, USA) geçirilmiştir. Daha sonra, UVVis spektrofotometrede (Shimadzu 2600, Shimadzu, Kyoto, Japan) ve 1-cm kalınlıkta tek kullanımlık küvet (Brand $\mathrm{GmbH}$, Wertheim, Germany) kullanılarak örneklerin $513 \mathrm{~nm}$ ve 700 $\mathrm{nm}$ 'de absorbans değerleri ölçülmüştür. Absorbans ölçümleri oda sıcaklığında ve kör olarak saf su kullanılarak gerçekleştirilmiştir. Antosiyanin içeriği malvidin-3-O-glukozid olarak hesaplanmış ve molekül ağırlığı $493.5 \mathrm{~g} \mathrm{~mol}^{-1}$ ve molar absorbans değeri $(\varepsilon) 28000 \mathrm{~L} \mathrm{~cm}^{-1}$ olarak hesaplama yapılmıştır. Ölçümler 3 tekerrür ve 2 paralelli olarak gerçekleştirilmiştir.

\section{Antioksidant aktivite}

Miller and Rice-Evans (1997) ile Arts ve ark., (2001) tarafından önerilen yöntem kullanılmıştır. $\mathrm{Bu}$ yöntem, $\quad \mathrm{ABTS} \bullet+\quad\left(2,2^{\prime}\right.$-azinobis-(3etilbenzotiazolin-6-sulfonik asit)) radikal katyonu tarafından tutulan antioksidatif maddelerin miktarının, sentetik bir antioksidan olan Troloks'un (suda çözünen $E$ vitamini analoğu) standart miktarlarıyla kıyaslanarak bağıl ölçümünü sağlamaktadır. Ölçümler, mavi/yeşil renkli stabil bir bileşik olan $\mathrm{ABTS}^{\circ+}$ radikalinin kayboluşunun $734 \mathrm{~nm}$ dalga boyunda spektrofotometrik olarak belirlenmesiyle yapılmıştır. Mavi/yeşil ABTS ${ }^{\bullet+}$ kromoforu oluşturmak için ABTS ve potasyum persülfat arasında gerçekleşen reaksiyondan yararlanılmıştır.

\section{Hardaliye antosiyaninlerinin depolama stabilitesi}

Hardaliye örneklerinin farklı sıcaklık derecelerinde depolanması sonucunda; toplam monomerik antosiyanin miktarı değişimi üzerine sıcaklığın etkisini belirlemek amacıyla iki farklı sıcaklıkta (4 ve $\left.20 \quad{ }^{\circ} \mathrm{C}\right)$ kinetik veriler hesaplanmıştır. Böylece hardaliyenin depolama stabilitesi belirlenmiş ve kinetik veriler ortaya konulmuştur.

\section{Reaksiyon hız sabitinin ( $k$ ) hesaplanması}

Hesaplanacak kinetik parametrelerden "hız sabiti (k)" reaksiyona giren bir maddenin miktarında ya da; reaksiyon sonunda oluşan herhangi bir ürünün miktarında, birim zamanda meydana gelen değişimleri gösteren parametredir.

Antosiyaninlerin parçalanması ve değişimine ilişkin değerler hem aritmetik hem de " $y$ " ekseni 10 tabanına göre düzenlenmiş yarı-log grafik kâğıdına işlenmiştir. Bu amaçla konsantrasyon değerleri önce herhangi bir transformasyon işlemi yapılmadan aritmetik ölçekli bir grafik kağıdının " $y$ " eksenine, süreler ise, " $x$ " eksenine işlenmiştir. Aynı şekilde, bu kez uygulanan her bir sıcaklık için antosiyanin kaybına ilişkin orijinal deney verileri herhangi bir transformasyon işlemi yapılmadan doğrudan yarı-logaritmik bir grafik kağıdının logaritmik ölçekli " $y$ " eksenine, süreler ise 
aritmetik ölçekli "x" eksenine işlenmiştir. Elde edilen eğrilere doğrusal regresyon analizi uygulanarak eğrilerin eğim ve intersept değerleri ile determinasyon katsayıları $\left(R^{2}\right)$ belirlenmiştir. Elde edilen $R^{2}$ eğrileri kıyaslanarak reaksiyonun sıfırıncı veya birinci derece olduğuna karar verilmiştir. $R^{2}$ değeri büyük olan eğriye ilişkin eğim değerleri kullanılarak aşağıda verilen 1 ve 2 No'lu eşitliğe göre reaksiyon hız sabitleri (k) hesaplanmıştır.

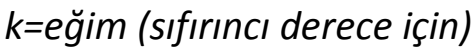 \\ $k=e g ̆ i m x 2.303$ (Birinci derece için)}

\section{Yarı ömür süresinin hesaplanması}

Yarı ömür süresi, antosiyaninlerin $\% 50$ 'sinin kaybı için gerekli süre olup, birinci derece kinetik modele uyan reaksiyonlar için 3 No 'lu eşitliğe göre hesaplanmıştır.

$$
t_{1 / 2}=-\ln (0.5) \times k^{-1}
$$

\section{Aktivasyon enerjisinin $\left(E_{a}\right)$ hesaplanması}

Reaksiyonun sıcaklık derecesine bağımlılık düzeyi, hem aktivasyon enerjisi $\left(E_{a}\right)$ hem de $Q_{10}$ değerinin hesaplanmasıyla belirlenmiştir. $E_{a}$ değeri, Arrhenius eşitliği yardımıyla 4 No 'lu eşitlik kullanılarak hesaplanmıştır.

$k=k_{o} \exp ^{-E a / R T}$

Hesaplamalarda 4 No 'lu eşitliğin, 5 No 'lu eşitlikte gösterilen formu kullanılmıştır.

$$
\ln k=\frac{-\mathrm{E}_{\mathrm{a}}}{--} \frac{1}{\mathrm{R}} \quad \frac{\mathrm{T}}{-}+\ln K_{o}
$$

Burada;

k: Hız sabiti (gün ${ }^{-1}$ ),

$\mathrm{K}_{\mathrm{a}}$ : Frekans faktörü (gün ${ }^{-1}$ ),

$E_{a}$ : Aktivasyon enerjisi $\left(\mathrm{kj} \mathrm{mol}^{-1}\right)$,

R: Gaz sabiti $\left(8.314 \times 10^{-3} \mathrm{~kJ} \mathrm{~mol}^{-1} \mathrm{~K}^{-1}\right)$,

T: Sıcaklık (K).

Aktivasyon enerjisinin hesaplanması amacıyla, antosiyaninlerin parçalanma reaksiyonuna ilişkin farklı sıcaklıklardaki hız sabitlerinin (k) doğal logaritmaları (Ink) aritmetik ölçekli bir grafiğin "y" eksenine ve sıcaklık değerlerinin (Kelvin) resiprokali (1/T) aynı grafiğin " $x$ " eksenine işlenerek, doğrusal bir eğri elde edilmiştir. Arrhenius grafiği denilen bu eğriye regresyon analizi uygulanmış ve elde edilen eşitliğin eğimi ile gaz sabiti çarpılarak, aktivasyon enerjisi hesaplanmıştır.

\section{$Q_{10}$ değerlerinin hesaplanması}

Reaksiyonun sıcaklığa bağımlılığını gösteren diğer bir boyut olan $Q_{10}$ değeri, sıcaklığın $10^{\circ} \mathrm{C}$ yükseltilmesinin reaksiyon hızına etkisini gösteren bir ölçüt olup, 6 No 'lu eşitlik kullanılarak hesaplanmıştır.

$$
Q_{10}=\left(k_{2} / k_{1}\right)^{10 /(\mathrm{T} 2-\mathrm{T} 1)}
$$

\section{Bulgular ve Tartışma}

Hardaliyenin depolanmasında antosiyaninlerin Isıl stabilitesi

Depolama süresince, uygulanan sıcaklığa bağlı olarak farklı aralıklarla alınan hardaliye örneklerinde antosiyanin kaybı belirlenmiştir. Hardaliye örnekleri 4 ve $20^{\circ} \mathrm{C}$ 'de 60 gün süre ile depolanmıştır. Örneklerin antosiyanin miktarlarındaki azalmaya ilişkin veriler Şekil 1 'de verilen grafikte gösterilmiştir.

Her bir depolama sıcaklığı için antosiyanin kaybına ilişkin değerlerin " $y$ " eksenine, sürelerin " $x$ " eksenine yerleştirilmesiyle, yarı logaritmik ölçekli bir grafikte doğrusal bir eğri elde edilmiştir. Bu durum, hardaliyede bulunan antosiyaninlerinin depolama sıcaklığına bağlı parçalanmasının her iki sıcaklık için birinci derece reaksiyon kinetiğine uyduğunu göstermektedir. Literatürde birçok üründe antosiyaninlerin parçalanmasının gerek ısıtma, gerekse de depolama süresince birinci dereceden kinetik modelle tanımlandığı görülmektedir (Tanchev ve Joncheva, 1973; Calvi ve Francis, 1978; Dyrby ve ark., 2001; Garzon ve Wrolstad, 2002). 


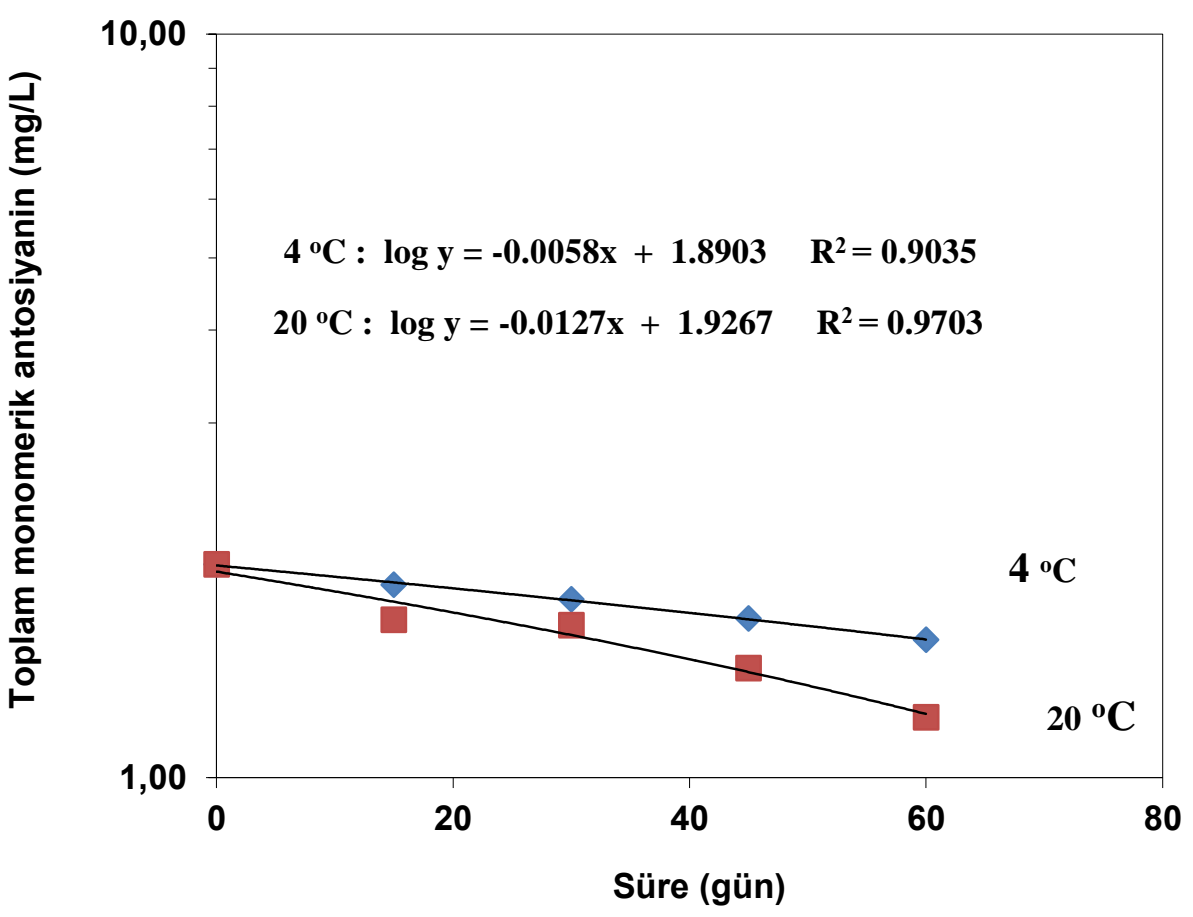

Şekil 1. Hardaliye örneklerinin farklı sıcaklıklarda depolanması süresince antosiyanin miktarındaki azalmalar.

Figure 1. Decrease in anthocyanin content of hardaliye samples during storage at different temperatures.

Hardaliyenin 4 ve $20{ }^{\circ} \mathrm{C}^{\prime}$ de depolanması sonucunda antosiyaninlerin parçalanmasına ilişkin kinetik katsayılar Çizelge 1 . 'de gösterilmiştir. Kinetik değerler incelenince, beklenildiği gibi depolama sıcaklığı yükseldikçe antosiyaninlerin parçalanma hızları artmıştır. Bu durum elde edilen $k$ hız sabitleri ile $t_{1 / 2}$ değerlerinin karşılaştırılmasıyla izlenebilmektedir. Hardaliyede antosiyaninlerin depolamada parçalanmasına ilişkin $t_{1 / 2}$ değerleri; 4 ve $20{ }^{\circ} \mathrm{C}$ 'lerde sırasıyla 22.50 gün ve 10.34 gün olarak saptanmıştır. $k$ değerlerinin sıcaklığa bağlı olarak artması ya da $t_{1 / 2}$ değerlerinin sıcaklığa bağlı olarak azalması karadut antosiyaninlerin sıcaklık artıkça hızla parçalandığını göstermektedir.

Çizelge 1. Hardaliye örneklerinin farklı sıcaklıklarda depolanması sırasında antosiyaninlerin parçalanmasına ilişkin kinetik parametreler.

Table 1. The kinetic parameters of anthocyanin degradation for hardaliye samples during storage at different temperatures.

\begin{tabular}{|c|c|c|c|c|c|c|}
\hline $\begin{array}{c}\text { Sicaklık } \\
\text { Temperature }\end{array}$ & $\begin{array}{c}\mathrm{R}^{2} \\
\text { Determinasyon } \\
\text { katsayısı } \\
\text { Determination } \\
\text { coefficients }\end{array}$ & $\begin{array}{l}\text { Eğim } \\
\text { Slope }\end{array}$ & $\begin{array}{c}\text { k } \\
\text { Hız sabiti } \\
\text { Rate } \\
\text { constant }\end{array}$ & $\begin{array}{c}\mathrm{t}_{1 / 2} \\
\text { (gün) } \\
\text { Yarılanma } \\
\text { süresi } \\
\text { Half-life value }\end{array}$ & $\begin{array}{c}\mathrm{Q}_{10} \\
\left(4^{\circ} \mathrm{C}-20^{\circ} \mathrm{C}\right)\end{array}$ & $\begin{array}{c}\mathrm{E}_{\mathrm{a}} \\
\text { Aktivasyon } \\
\text { enerjisi }\left(\mathrm{kJ} \mathrm{mol}^{-1}\right) \\
\text { Activation } \\
\text { energy }\left(\mathrm{kJ} \mathrm{mol}^{-1}\right)\end{array}$ \\
\hline $4{ }^{\circ} \mathrm{C}$ & 0.9035 & -0.0134 & 0.0308 & 22.50 & 1.63 & 64.76 \\
\hline $20{ }^{\circ} \mathrm{C}$ & 0.9703 & -0.0291 & 0.0670 & 10.34 & & \\
\hline
\end{tabular}

Literatürde hardaliyedeki antosiyaninlerin stabilitesine ilişkin çalışmalara rastlanmamıştır. Bununla birlikte, literatürde antosiyanin içeren farklı meyve suyu veya konsantrelerine ait çalışmalar bulunmaktadır. Örneğin üzüm suyu antosiyaninlerinin termal parçalanmasına ilişkin $t_{1 / 2}$ değerleri 70,80 ve $90{ }^{\circ} C^{\prime}$ lerde sırasıyla 21.2 , 10.6 ve 5.2 saat olarak saptanmıştır (Hillmann ve ark., 2011). Böğürtlen konsantrelerindeki antosiyaninlerin depolama stabilitesinin belirlendiği bir çalışmada $\left(5,25\right.$ ve $\left.37^{\circ} \mathrm{C}\right)$ depolama sıcaklığı ve süresi arttıkça antosiyaninlerin parçalanma hızının da arttığı yer almıştır (Wang ve Xu, 2007). Antosiyaninlerin parçalanmasına ilişkin $t_{1 / 2}$ süresi, $5{ }^{\circ} C^{\prime}$ de 138.6 gün olduğu halde, depolama sıcaklığı $25^{\circ} \mathrm{C}^{\prime}$ ye 
yükselince 19.7 güne ve $37^{\circ} C^{\prime}$ ye yükselince ise, 9.4 güne düştüğü saptanmıştır. Aynı çalışmada, böğürtlen konsantrelerinin $5-37{ }^{\circ} \mathrm{C}$ sıcaklıklarda depolanması süresince $E_{a}$ değeri $75.5 \mathrm{~kJ} \mathrm{~mol}^{-1}$ olarak belirlenmiştir. Bunun dışında, $25{ }^{\circ} \mathrm{C}$ 'de depolanan çilek suyu konsantrelerinde $\left(65^{\circ} \mathrm{Bx}\right)$ $\mathrm{t}_{1 / 2}$ değeri, 3.5 gün olarak saptanmıştır (Garzon ve Wrolstad, 2002). Türkyılmaz (2009), siyah $5^{\circ} \mathrm{C}$, $20^{\circ} \mathrm{C}$ ve $30^{\circ} \mathrm{C}$ 'de depolanan siyah havuç suyu konsantresindeki (64 $\left.{ }^{\circ} \mathrm{Bx}\right)$ antosiyaninlerin parçalanmasına ilişkin $t_{1 / 2}$ değerlerini sırasıyla; 20.1, 4.6 ve 1 ay ve aynı sıcaklılardaki $E_{a}$ değerini ise, $84 \mathrm{~kJ} \mathrm{~mol}^{-1}$ olarak saptamıştır. Nar suyu konsantrelerinde ise, $\mathrm{t}_{1 / 2}$ değerleri $5^{\circ}, 12^{\circ}$ ve 20 ${ }^{\circ} \mathrm{C}$ 'lerde sirasıyla; 7.2, 2.6 ve 1 ay olarak belirlenmiştir (Turfan, 2008). Bu değerlerle kıyaslanınca, hardaliye antosiyaninlerinin, depolama sürecinde; diğer tüm meyve sularından daha az stabil olduğu görülmektedir. Ancak, hardaliye ile diğer meyve sularının antosiyanin içeriği arasında farklılıklar mevcut olup bu farklılıklar reaksiyon hızını etkileyebilmektedir. Bilindiği üzere, birinci derece reaksiyonların hızı reaktan konsantrasyonu ile orantılı değişmektedir. Birinci derece reaksiyonlarda substrat konsantrasyonu arttıkça reaksiyon hızı da artmaktadır (Özkan ve ark., 2011). Ayrıca, meyveler arasındaki antosiyanin kompozisyonlarının değişiklik göstermesi ısıl ve depolama stabiliteleri açısından da farklılık oluşturabilecektir.

Hardaliye örneklerinin depolama süresince antosiyanin kaybının sıcaklığa bağııı̆ı̆ın saptanması amacıyla; aktivasyon enerjisi ( $\mathrm{Ea}$ ) ve $\mathrm{Q}_{10}$ değerleri hesaplanmıştır (Çizelge 1 ). $4-20{ }^{\circ} \mathrm{C}$ arasında, karadut suyu örneklerinde antosiyaninlerin parçalanmasına ilişkin aktivasyon enerjisi değeri (Ea), $64.76 \mathrm{~kJ} \mathrm{~mol}^{-1}$ olarak hesaplanmıştır (Çizelge 1).

Literatürde farklı meyve suları için benzer Ea değerleri saptanmıştır. Örneğin, bu değer; böğürtlen sularında $59 \mathrm{~kJ}$ mol-1 (Wang ve Xu

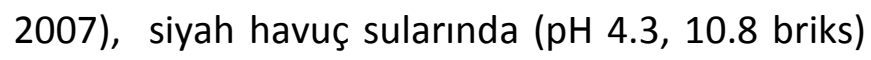
$62.5 \mathrm{~kJ}$ mol-1 (Kırca, 2004) ve üzüm sularında 72 kJ mol-1 olarak saptanan değerlere yakın bir değerdir (Hillmann ve ark., 2011). Literatürde, antosiyanin gibi suda çözünür pigmentlerin parçalanmasına ilişkin aktivasyon enerjisinin genel olarak 63-126 kJ mol${ }^{-1}$ civarında olduğu bildirilmektedir (Nielsen ve ark., 1993).

Elde edilen veriler, hardaliye örneklerindeki antosiyaninlerin depolama sıcaklığı ve süresine bağıı olarak parçalandığını göstermiştir. Antosiyaninlerin parçalanmasında en önemli etken ortamdaki oksijen varlığıdır. Oksidasyon reaksiyonları, sıcaklık arttıkça hızlanmaktadır. Antosiyaninlerin oksidatif olarak parçalanmasındaki ilk aşama flavilyum katyonundaki C halkasının açılması ve çalkon meydana gelmesidir. Buna karşın, Adams (1973), antosiyaninlerin yapısında bulunan şekerlerin hidrolizasyonu sonucu aglikon oluşumunu antosiyanin parçalanmasının başlangıç aşaması olarak tanımlamıştır.

Depolama sürecince, hardaliye örneklerine ait polifenol içeriği ve antioksidan aktivite değişimi de incelenmiştir. Literatürde polifenol içeriğinin sıcaklıkla doğru orantılı olarak değişim gösterdiği yönünde çalışmalar mevcut olmakla birlikte, sıcaklık ile önemli değişim göstermediği yönünde de çalışmalar oldukça fazladır. Hardaliye örneklerinin polifenol içeriğinde $4{ }^{\circ} \mathrm{C}$ ve $20^{\circ} \mathrm{C}$ için sırasıyla \% 21 ve \% 24 kayıp meydana gelmiştir (Şekil 2). Hardaliyenin farklı sıcaklıklarda depolanması süresince, toplam polifenol miktarındaki değişimin herhangi bir kinetik modele uymadığı görülmüştür. Elde edilen veriler, toplam polifenol miktarının düşük sıcaklıklardan önemli miktarda etkilenmediğini, artan sıcaklıkla birlikte polifenol miktarındaki değişimin daha belirgin şekilde meydana geldiğini ortaya koymuştur. Antioksidan aktivite içeriği ise önemli değişim görülmemiş, her iki sıcaklık değerinde de \% 12-13 oranında azaldığı saptanmıştır (Şekil 3).

Turfan (2008) tarafından yapılan bir araştırmada nar suyu konsantrelerinin 150 gün süresince $4{ }^{\circ} \mathrm{C}$ 'de depolama sonrası toplam antioksidan aktivite değerlerinde azalış belirlenmiştir. Araştırıcılar; durultulmamış nar suyunun, depolama öncesi $31.45 \mathrm{mM}$ olan toplam antioksidan aktivite değerinin 150 . gün sonunda $27.14 \mathrm{mM}$ 'a düşerek \%13.7 oranında; 
durultulmuş berrak nar suyu örneği için de, depolama başlangıcında antioksidan aktivite $21.61 \mathrm{mM}$ iken, depolama sonunda $18.98 \mathrm{mM}$ 'a düşerek \% 12.2 oranında ve konsantreden hazırlanan nar suyu için de, bu değer depolama başlangıcında $20.31 \mathrm{mM}$ iken, depolama sonunda 19.07 mM'a düşerek \% 6.1 oranında azaldı̆̆ı saptanmıştır.

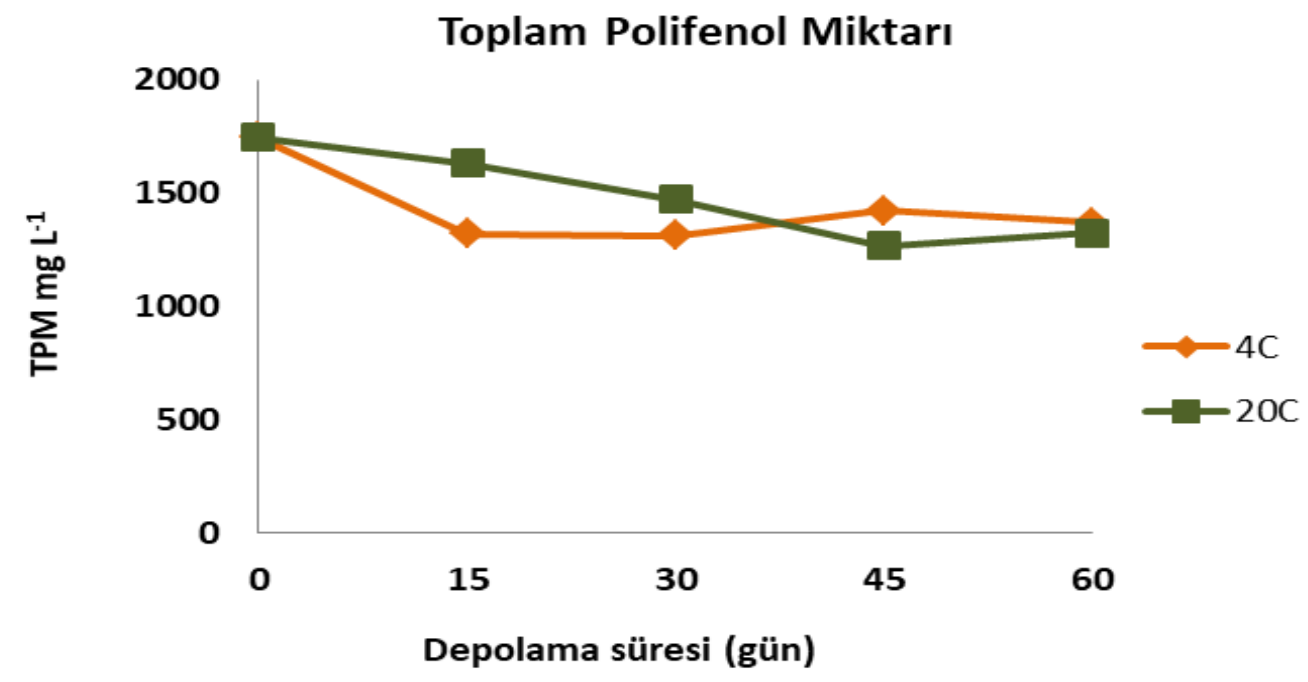

Şekil 2. Hardaliye örneklerinin farklı sıcaklıklarda depolanması süresince toplam polifenol miktarındaki azalmalar. Figure 2. Decrease in total polyphenol content of hardaliye samples during storage at different temperatures.

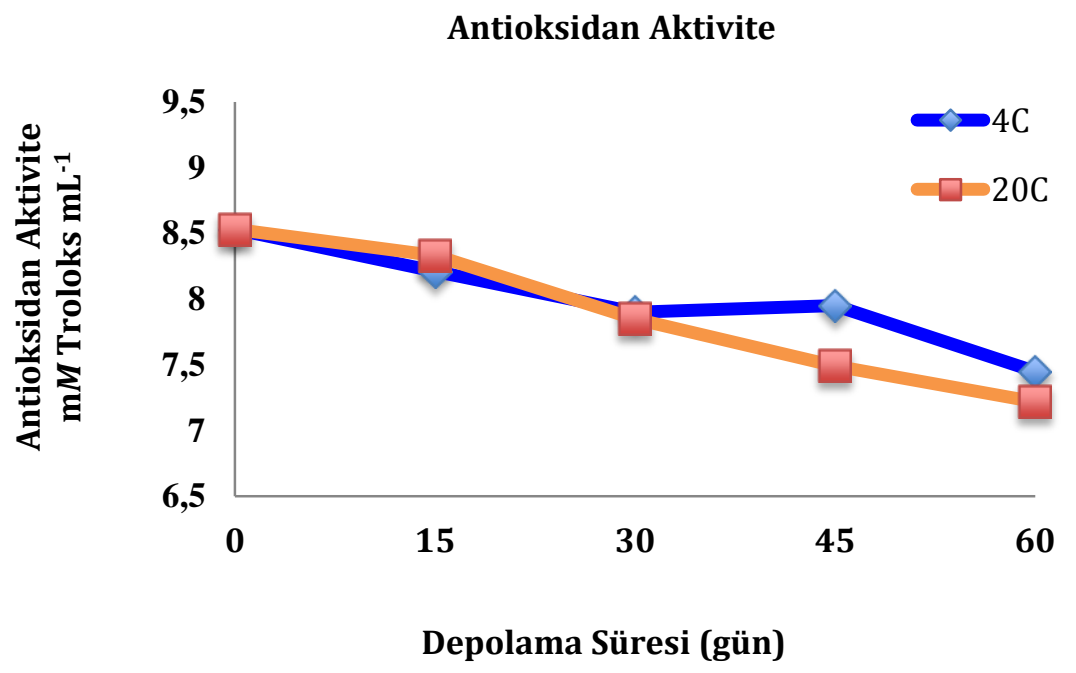

Şekil 3. Hardaliye örneklerinin farklı sıcaklıklarda depolanması süresince antioksidan aktivite değerindeki değişim. Figure 3. Decrease in antoxidant activity of hardaliye samples during storage at different temperatures.

Klimczak ve ark., (2007), portakal sularını 18, 28 ve $38{ }^{\circ} \mathrm{C}$ 'lerde sırasıyla 6 ay süre ile depolayarak antioksidan aktivitedeki değişimi DPPH yöntemi ile incelemişlerdir. Sıcaklık artışıyla birlikte antioksidan aktivite değerlerinin sırasıyla \% 14.22, \%44.30 ve \% 80.69 azaldığı saptanmıştır. Diğer bir çalışmada ise, yaban mersini suyu ve konsantrelerinin $25{ }^{\circ} \mathrm{C}^{\prime}$ de 6 ay depolanması sonucunda antioksidan aktivite değerinin yalnızca \%9 azaldığı belirlenmiştir (Brownmiller, 2008).
Çalışmamızda hardaliyenin depolama süresince, renk kaybının sıcaklığa ve depolama süresine bağı olarak arttığı belirlenmiştir. Bu süreç, monomerik antosiyaninlerin parçalandığını ve esmer pigmentlerin oluştuğunu, yani doğal rengin bozulduğunu göstermektedir.

Antosiyanin kaybı, fenolik madde kaybı ve antioksidan aktivite değerinde meydana gelen azalmayı sınırlandırmak için, hardaliyenin düşük sıcaklıklarda muhafaza edilmesi önerilmektedir. 


\section{Sonuç}

\section{Depolama sırasında hardaliyenin renk} stabilitesini araştıran bu çalışmada, hardaliye antosiyaninlerinin diğer meyve sularındaki antosiyanin kaynaklarına göre daha az stabil olduğu ve fenolik maddelerin depolama sıcaklığından önemli düzeyde etkilenmediğini açıkça ortaya koyulmuştur. Buna rağmen, antosiyanin parçalanmasını en aza indirmek için; hardaliyenin düşük sıcaklıklarda depolanması önem taşımaktadır.

\section{Kaynaklar}

Adams, JB. (1973). Thermal Degradation of Anthocyanins with Particular Reference to the 3-Glycosides of Cyanidin. I. In acidified aqueous solutions at $100^{\circ}$. Journal of the Science of Food and Agriculture, 24, 747-762. DOI: 10.1002/jsfa.2740240702

Anonim. (2012). http://www.ellez.com.tr/hardaliyeTarihi. aspx, Erişim tarihi: 11.08.2012, 17:30.

Arıcı, M. (2007). Hardaliye: Fermentierter Traubensaft - Ein Traditionelles Türkisches Getränk. Ernährung, Ernaehrung, 31, 3, 171-172. DOI: 10.1016/j.tplants.2008.09.008

Arıcl, M., Coşkun, F., Mirik, M., \& Gülcü, M. (2011). Hardaliyeden Laktik Asit Bakterilerinin İzolasyonu, Tanımlanması, Teknolojik ve Probiyotik Özelliklerinin Belirlenmesi, Proje No: 1100018.

Arts, M.J.T.J., Haenen, G.R.M.M., Voss, H.P., \& Bast, A. (2001). Masking of Antioxidant Capacity by the Interaction of Flavonoids with Protein. Food and Chemical Toxicology, 39, 787-791. DOI: article/pii/S0278691501000205

Brownmiller, C., Howard, L.R., \& Prior RL. (2008). Processing and storage effects on monomeric anthocynins.percent polymeric colour and antioxidant capacity of processed blueberry products. Journal of Food Science, 5(73), 1216-1218. DOI: 10.1111/j.1750-3841.2008.00761.x.

Calvi, J.P., Francis, F.J. (1978). Stability of Concord grape (V. Labrusca) anthocyanins in model systems. Journal of Food Science, 43, 1448-1456. DOI: 10.1111/j.13652621.1978.tb02517.x

Castilla, P., Echarri, R., Davalos, A., Cerrato, F., Ortega, H., Teruel, J.L., Lucas, M.F., Gomez-Coronado, D., Ortuno, J.., \& Lasuncion, M.A. (2006). Concentrated Red Grape Juice Exerts Antioxidant, Hypolipedemic and Antiflammatory Effects in Both Hemodialysis Patient sand Healthy Subjects. American Journal of Clinical Nutrition, 84, 252-262. DOI: 10.1093/ajcn/84.1.252

Coşkun, F. (2001). Hardaliye Üretim Teknolojisi Üzerine Bir Araştırma, (Doctoral dissertation). Retrieved from https://www.ulusaltezmerkezi.net/searchwpsolr/?search=Hardaliye+\%C3\%9Cretim+Teknolojisi +\%C3\%9Czerine+Bir+Ara\%C5\%9Ft\%C4\%B1rma\%2C+
Davalos, A, Bartolome, B, \& GomezCordoves, C. (2006). Antioxidant Properties of Commercial Grape Juices and Vinegars. Food Chemistry, 93 (2), 325- 330. DOI: 10.1016/j.foodchem.2004.09.030

Dyrby, M., Westergaard, N., \& Stapelfeldt, H. (2001). Light and Heat Sensitivity of Red Cabbage Extract in Soft Drink Model System. Food Chemistry, 72, 431- 437. DOI: 10.1016/S0308-8146(00)00251-X

Fuleki, T., Francis, F.J. (1968). Quantitative Methods for Anthocyanins, 2. Determination of Total Anthocyanin and Degradation Index for Cranberry Juice. Journal of Food Science, 33, 78-82. DOI: 10.1111/j.13652621.1968.tb00888.x

Garzon, G.A., Wrolstad, R.E. (2002). Comparison of the Stability of Pgargonidin-based Anthocynins in Strawberry Juice and Concentrate. Journal of Food Science, 67 (4), 1288-1299. DOI: 10.1111/j.13652621.2002.tb10277.x

Giusti, M.M., Wrolstad, RE.. (2001). Unit F1.2. Anthocynins. Characterization and Measurement with UV-visible Spectroscopy, p. 1-13. In Current Protocols in Food Analytical Chemistry. Wrolstad.R.E. and Schwartz. S.J. (eds.). John Wiley and Sons., New York.

Hager, A,. Howard, L.R., Prior, R.L.B, \& Rownmiller, C. 2008. Processingand Storage Effects on Monomeric Anthocynins, Percent Polymeric Color and Antioxidant Capacity of Processed Black Raspberry Products. Food Nutrition and Health, 73 (6), 134-140. DOI: 10.1111/j.1750-3841.2008.00855.x

Hillmann, M.C.R., Burin, V.M., \& Bordignon-Luiz, M.T. 2011. Thermal Degradation Kinetics of Anthocynins in Grape Juice and Concentrate. International Journal of Food Science and Technology, 46, 1997-2000. 10.1111/j.1365-2621.2011.02694.x

İnanç, A.L., Yüksel, D. (2018). Ihlamur Bitkisinin (Tilia cordata) Katı-SıVı Ekstraksiyonunda Toplam Fenolik Madde Kinetiğinin Matematiksel Modellenmesi. Harran Tarım ve Gıda Bilimleri dergisi, 22(1), 12-20. DOI: 10.29050/harranziraat.315709

Kırca, A. (2004). Siyah Havuç Antosiyaninlerinin Bazı Meyve Ürünlerinde Isıl Stabilitesi. (Doctoral dissertation). Retrieved from http://acikarsiv.ankara.edu.tr/browse/1584/

Klimczak, I., Małeckaa, M., Szlachtaa, M., \& GliszczyńskaŚwigło, A. (2007). Effect of Storage on the Content of Polyphenols, Vitamin C and the Antioxidant Activity of Orange Juices. Journal of Food Composition and Analysis, $20 \quad$ (3-4), 313-322. DOI: 10.1016/j.jfca.2006.02.012

Mazza G., Miniati E. (1993). Anthocyanins in Fruits, Vegetables and Grains. Boca Raton, CRC Press Inc.: 1-28.

Mazza G., Francis F.J. (1995). Anthocyanins in grapes and grape products. Critical Reviews in Food Science and Nutrition, 35, 341-371. DOI: 10.1080/10408399509527704

Miller, N.J., Rice-Evans, C.A. (1997). The Relative Contributions of Ascorbic Acid and Phenolic Antioxidants to The Total Antioxidant Activity of Orange and Apple Fruit Juices and Black currant Drink, Food Chemistry, 60, 331-337.

Nielsen, S.S., Marcy, J.E., \& Sadler, G.D. (1993). Chemistry of aseptically processed foods, pp. 87-111. In: J.V. 
Chambers and P.E. Nelson, Editors, Principles of aseptic processing and packaging, Food Processors Institute, Washington, DC.

Özkan, M., Cemeroğlu, B., \& Toklucu, A.K. (2011). Reaksiyon Kinetiği. Reaksiyon kinetiği, Özkan, M., (ed.), Bizim grup basımevi, Ankara, 110s.

Pala, C.U., Toklucu, A.K. (2013). Effects of UV-C light Processing on Some Quality Characteristics of Grape Juices. Food Bioprocess Technology, 6(3), 719-725. 10.1007/s11947-012-0808-7

Pozo-Insfran, D.D., Balaban. M.O., \& Talcott, S.T. (2006). Enhancing the Retention of Phytochemicals and Organoleptic Attributes in Muscadine Grape juice Through a Combined Approach Between Dense Phase $\mathrm{CO}_{2}$ Processing and Copigmentation. Journal of Agricultural and Food Chemistry, 54, 6705-6712. DOI: 10.1021/jf060855g

Pozo-Insfran, D.D., Follo-Martinez, A.D., Talcott, S.T., \& Brenes, C.H. (2007). Stability of Copigmented Anthocyanins and Ascorbic Acid in Muscadine Grape Juice Processed by High Hydrostatic Pressure. Journal of Food Science, 72, 247-253. 10.1111/j.17503841.2007.00316.x

Sadilova, E., Carle, R., \& Stintzing, F.C. (2007). Thermal Degradation of Anthocyanins and Its Impact on Colour and in Vitro Antioxidant Capacity. Molecular Nutrition and Food Research, 51, 1461-1471. DOI: 10.1002/mnfr.200700179
Tanchev, S.S., Joncheva, N. (1973). Kinetics of the Thermal Degradation of Cyanidin-3-Rutinoside and Peonidin3-Rutinoside. Z. Lebensm. Unters.-Forsch. 153, 37-41. DOI: 10.1007/BF01267717

Tiwari, A.D., Munshi, R., Kumar, R.N., Pandey, A, Arora, J.S., \& Bhat, A.K. (2010). Sureja Effect of Salt Stress on Cucumber: $\mathrm{Na}+\mathrm{K}+$ Ratio, Osmolyte Concentration, Phenols and Chlorophyll Content. Acta Physiol. Plant, 32: 103-114. DOI: 10.1007/s11738-009-0385-1

Turfan, Ö. (2008). Nar Suyu Konsantresi Üretimi ve Depolama Sürecinde Antosiyaninlerdeki Değişimler. (Master dissertation). Retrieved from http://acikarsiv.ankara.edu.tr/browse/3402/

Turfan, Ö., Türkyılmaz, M., Yemiş, O., \& Özkan, M. (2011). Anthocyanin and Colour Changes during Processing of Pomegranate (Punica granatum L., CV. Hicaznar) Juice from Sacs and Whole Fruit. Food Chemistry, 129, 1644-1651. DOI: 10.1016/j.foodchem. 2011.06.024

Türkyılmaz, M. (2009). Siyah Havuç Konsantresi Üretimi ve Depolama Sürecinde Renkteki Değişimler. (Doctoral Preparatory Study). Retrieved from http://acikarsiv. ankara. edu.tr/ browse/5339/

Wang, W.D., Xu, S.Y. (2007). Degradation Kinetics of Anthocynins in Blackberry Juice and Concentrate. Journal of Food Engineering, 82, 271-275. DOI: 10.1016/j.jfoodeng.2007.01.018 